\title{
Caminhada da Fé: uma hermenêutica da devoção mariana à Aparecida
}

\author{
Walk of Faith: \\ a hermeneutic of marian devotion to Aparecida
}

Rosiléa Archanjo de Almeida

\section{Resumo}

O presente artigo apresenta a peregrinação a pé feita por fiéis da cidade de Juiz de Fora à Aparecida (SP), onde localiza-se o Santuário Nacional em honra à Nossa Senhora da Conceição Aparecida, considerada pelos católicos, a padroeira do Brasil. Analisamos os discursos dos peregrinos juiz-foranos e de outras cidades que percorrem o trajeto de aproximadamente $300 \mathrm{Km}$ na chamada "Caminhada da Fé". Os peregrinos enfrentam no percurso, adversidades, como calo nos pés, cansaço corporal e mental. Sabendo de tais condições, nos questionamos: o que motiva os devotos a participar desta Caminhada? Para chegar aos objetivos deste artigo, analisamos os discursos dos caminhantes, a partir da série "Fé na Estrada", publicada no jornal impresso Tribuna de Minas, e em suas mídias sociais. A fé é apresentada como o principal motivo para a participação na Caminhada, entretanto, observamos que além da fé, a pertença a um grupo social estimula a participação na Caminhada da Fé.

Palavras-Chave: Caminhada da Fé. Nossa Senhora Aparecida. Peregrinação. Devoção. Discurso.

\begin{abstract}
This article presents the pilgrimage on foot made by faithful from the city of Juiz de Fora to Aparecida (SP), where is located the National Shrine in honor of Our Lady of Conception Aparecida, considered by Catholics, the patron saint of Brazil. We analyzed the speeches of the pilgrims born in Juiz de Fora and other citiezens that travel the approximately $300 \mathrm{Km}$ in the so-called
\end{abstract}


"Walk of Faith". Pilgrims face adversity such as calluses on feet, body and mental fatigue. Knowing these conditions, we ask ourselves: what motivates devotees to participate in this walk? To reach the objectives of this article, we analyze the speeches of walkers, from the series "Faith on the Road", published in the print newspaper Tribuna de Minas, and in their social media. Faith is presented as the main reason for participating in the Walk, however, we noticed that in addition to faith, belonging in a social group encourages participation in the Walk of Faith.

Keywords: Faith walk. Our Lady Aparecida. Pilgrimage. Devotion. Speech.

\section{Introdução}

A "Caminhada da Fé" é o objeto de pesquisa deste artigo. Peregrinos juiz-foranos iniciaram em 2012 um trajeto a pé de Juiz de Fora (MG), até o Santuário Nacional de Aparecida no interior do estado de São Paulo. Este percurso foi idealizado por Marco Aurélio, que no ano anterior, em 2011, havia participado de uma peregrinação semelhante de Cambuquira (MG) à Aparecida (SP), e demonstrou o interesse de que Juiz de Fora tivesse uma romaria desse tipo ao Santuário Nacional. Conforme entrevista com Marco Aurélio, ${ }^{1}$ a primeira Caminhada contou com a participação de doze amigos, que sem estrutura e logística, planejaram um percurso da cidade mineira ao destino paulista.

No trecho de aproximadamente $300 \mathrm{Km}$, apenas $97 \mathrm{Km}$, ou seja, os três últimos dias de Caminhada, são percorridos em rodovia, referente à Rodovia Presidente Dutra. Os demais são caminhados em estrada de chão.

Aurélio $^{2}$ ainda ressalta que durante o trajeto, os peregrinos passam por mudanças climáticas, interferências corporais e mentais, provenientes do cansaço de uma caminhada prolongada. Daí questionamos: o que leva tais caminhantes a participarem desse tipo de peregrinação, mesmo sabendo das adversidades enfrentadas no percurso? Observamos que a fé e a devoção mariana são os principais fatores que os motivam. Entretanto, demonstraremos no decorrer deste artigo, que a Caminhada da Fé vai além do envolvimento religioso.

Além de pesquisas bibliográficas, em particular, a perspectiva teórica adotada por Eade \& Sallnow, ${ }^{3}$ nosso artigo terá como foco a interpretação do

\footnotetext{
${ }^{1}$ AURÉLIO, M., Fé na estrada.

${ }^{2}$ AURÉLIO, M., Fé na estrada.

${ }^{3}$ EADE, J; SALLNOW, E., Contesting the Sacred, p. 5.
} 
fenômeno da peregrinação, analisando a diversidade de discursos dos presentes na peregrinação. Direcionando, especialmente, nossa atenção para a diversidade sociocultural dos participantes nas dimensões constitutivas do objeto de estudo.

Analisamos os discursos dos peregrinos e dos organizadores da Caminhada da Fé, realizada entre os dias 17 e 26 de julho de 2019, a partir da série "Fé na Estrada", publicada no jornal Tribuna de Minas. Tais relatos nos levam a uma hermenêutica dos discursos dos caminhantes.

Sabemos que as peregrinações à Aparecida já foram temas de diversos artigos, dissertações e teses. Existem estudos que se debruçam sobre estas peregrinações a partir da ótica do turismo religioso no Brasil e outros a partir da ótica dos "caminhos devocionais". Nesse artigo, retomamos a este tema, inclusive utilizando alguns desses estudos. Nosso intento é ampliar o conhecimento acerca desse importante fenômeno religioso brasileiro, a partir de uma peregrinação, com um trajeto diferente dos demais, com as diferentes formas da expressão religiosa dos peregrinos juiz-foranos e de outras cidades brasileiras, que vão até Juiz de Fora para se juntarem ao grupo mineiro.

Nos baseando em Calvelli a "Caminhada da Fé" é uma peregrinação onde se dá a aplicação da experiência religiosa individual a partir da fé, e para além, passa a ser também um "lugar" de entrelaçamento coletivo e social, pois a "transformação que a peregrinação opera é capaz de acionar valores e práticas centradas no compromisso social com o outro. $\mathrm{O}$ ethos do ser peregrino condensa atitudes e visões de mundo voltadas para o bem-estar coletivo como condição determinante das realizações individuais". ${ }^{5}$

Jaqueline Moreira reforça o traço de tradição das peregrinações e acredita numa "mudança" dos caminhantes após participarem dos trajetos; "os sujeitos, ao mesmo tempo em que carregam consigo algumas 'tradições', que pertencem a um valor de ordem superior denominado 'conservação', também estavam prédispostos à 'abertura à mudança". 6

Em 2019, a "Caminhada da Fé" foi realizada pela sétima vez, com a participação de oitenta e sete participantes.

\footnotetext{
${ }^{4}$ CALVELLI, H. G., A “Santiago de Compostela” brasileira, p. 28.

${ }^{5}$ CALVELLI, H. G., A "Santiago de Compostela" brasileira, p. 14.

${ }^{6}$ MOREIRA, J. C. C., "Caminho da Fé”, p. 205.
} 


\section{A devoção à Nossa Senhora Aparecida}

Explanamos neste item a história da aparição da imagem de Nossa Senhora da Conceição, que posteriormente tornou-se a padroeira do Brasil sob o título de Aparecida, levando milhares de fiéis ao seu Santuário Nacional. Motivados pela fé e promessas alcançadas os devotos realizam peregrinações em agradecimento, como o "Caminho da Fé", que hoje recebe ampla divulgação, incentivo público e privado para a promoção do turismo religioso, observado por Silveira. ${ }^{7}$

Conforme Moreira, ${ }^{8}$ a devoção à Nossa Senhora Aparecida remonta a outubro de 1717, quando os pescadores Domingos Martins Garcia, João Alves e Felipe Pedroso organizavam uma pescaria em favor à comitiva do $2^{\circ}$ Conde de Assumar, Dom Pedro Miguel de Almeida Portugal, $3^{\circ}$ governador da capitania de São Paulo, que estava visitando a região de Guaratinguetá. Ao lançarem suas redes nas águas do Rio Paraíba, após tentativas frustradas, depararam com uma imagem de Nossa Senhora da Conceição, que se encontrava sem a cabeça e coberta pelo lodo do rio. Prosseguindo o trabalho, lançaram novamente a rede e resgataram a cabeça da mesma "santa", e a partir daí a pescaria fez-se em abundância.

O fato rapidamente se espalhou levando os moradores do Vale do Paraíba a chamar a imagem de a "Aparecida", ficando por quinze anos com a família de um dos pescadores. Em uma taipa de pilão, foi construído um local para o culto onde rezava-se o terço. No caminho de Itaguaçú, por volta de 1745, foi construída a capela do Morro dos Coqueiros, para abrigar a imagem, iniciando as romarias e formando-se uma vila ao redor da capela. Na sequência, a imagem foi transferida para a igreja matriz ou Basílica Velha, que teve suas obras concluídas em $1888 .{ }^{9}$

No dia 08 de setembro de 1904, realizou-se a festa de coroação por aprovação oficial da Igreja, através do papa Pio X. Na ocasião a Princesa Isabel doou uma coroa de ouro 24 quilates e realizou a jura, registrada nos livros da Cúria da Basílica: "aos vossos pés, nesse santuário, o Brasil lhes promete para sempre, trazer suas flores, acender seus filhos e cantar seus louvores". ${ }^{10}$

A vila chamada de Capela foi emancipada de Guaratinguetá em 1928. No ano seguinte, Nossa Senhora foi proclamada oficialmente a padroeira e "Rainha do Brasil", por provisão do Papa Pio XI. E a partir de 11 de novembro

${ }^{7}$ SILVEIRA, E. S., Turismo religioso no Brasil, p. 38.

${ }^{8}$ MOREIRA, J. C. C., "Caminho da Fé”, p. 52.

${ }^{9}$ MOREIRA, J. C. C., "Caminho da Fé”, p. 52.

${ }^{10}$ MENDES, G.; MARCOVICCHIO, M., Nossa Senhora Aparecida. 
de 1955, começou a ser construída a nova Basílica, inaugurada em 1984, ${ }^{11}$ com a colaboração dos donativos de devotos.

A Basílica atual foi erguida "numa área de $23.200 \mathrm{~m}^{2}$, abrangendo uma área coberta de $19.000 \mathrm{~m}^{2}$ e comportando uma lotação de, aproximadamente, 70 mil pessoas, exigiu 35 mil metros cúbicos de concreto e 15 milhões de tijolos". ${ }^{12}$ Em 2003, durante a Assembleia Geral da Conferência Nacional dos Bispos do Brasil, a basílica foi declarada oficialmente, como o maior Santuário Mariano do mundo, por sua magnitude, projeção, organização e pastoral.

Os traços históricos, as narrativas de milagres e a consequente devoção mariana reforçam o motivo das peregrinações realizadas ao Santuário Nacional, como é o caso das caminhadas semelhantes a do "Caminho da Fé".

O "Caminho da Fé" é um percurso onde fiéis dos estados de São Paulo e de Minas Gerais seguem em direção ao Santuário Nacional, local próximo onde a imagem foi encontrada por pescadores no Rio Paraíba. Este caminho foi baseado no "Caminho de Santiago de Compostela", na Espanha. O roteiro foi preparado com trajetos por trilhas e estradas rurais. Há sinalização e uma infraestrutura capaz de receber os peregrinos nos principais pontos de parada credenciados para acomodação e passagem até o Santuário Nacional.

Moreira ${ }^{13}$ recorda que Sr. Almiro Grings foi quem idealizou o projeto que contou com a adesão de dezenove paróquias, cidades e prefeituras, envolvendo três dioceses católicas, e instituições privadas. $\mathrm{O}$ percurso inicial foi inaugurado em 11 de fevereiro de 2003, saindo da cidade de Águas da Prata (SP). Seu primeiro prolongamento ocorreu em junho do mesmo ano, em função dos milagres atribuídos à figura beata de Pe. Donizetti e sua devoção à Nossa Senhora da Aparecida. Foi acrescentada, dessa forma, a cidade de Tambaú (SP) que passou a ser o marco zero do trajeto.

Com o aumento da divulgação, inclusive internacional, a partir de 2005, o "Caminho da Fé" sofreu algumas modificações, tendo conhecido, em 2006, o seu segundo prolongamento. ${ }^{14}$ Foram incluídos os trechos de Mococa (SP), São José do Rio Pardo (SP), São Sebastião da Grama (SP) e São Roque da Fartura (SP), os trechos já previstos. Os trechos de Paraisópolis (MG) à São Bento do Sapucaí (SP), Sapucaí Mirim (MG), Santo Antônio do Pinhal (SP) à Pindamonhangaba (SP) foram exluídos do trajeto por decisão da Assembléia Geral da Associação dos Amigos do Caminho da Fé. Incluiu-se, também, o

${ }^{11}$ Embora tenha sido inaugurada oficialmente nessa data, ainda nos dias de hoje, a Basílica passa por obras de ampliação estrutural.

${ }^{12}$ MOREIRA, J. C. C., "Caminho da Fé”, p. 54.

${ }^{13}$ MOREIRA, J. C. C., "Caminho da Fé", p. 48.

${ }^{14}$ MOREIRA, J. C. C., "Caminho da Fé”, p. 50. 
percurso saíndo de Paraisópolis (MG) passando por Brazópolis (MG), Distrito de Luminosa (MG), Distrito Campista (MG), Campos de Jordão (SP), Pindamonhangaba (SP), Roseira (SP) até Aparecida (SP).

Moreira ${ }^{15}$ afirma que o "Caminho da Fé" pode ser comparável ao "Caminho de Santiago de Compostela", por incrementação do percurso e distância total da rota. Os participantes levam entre 14 a 21 dias para chegar à Aparecida, caminhando de 20 a $30 \mathrm{~km}$ diários a partir de Tambaú. Assim como este caminho, apresentamos a seguir, o percurso que parte da cidade de Juiz de Fora e que ganha o nome de "Caminhada da Fé".

\section{Breve histórico da Caminhada da Fé}

Como já expomos neste artigo, a Caminhada da Fé de Juiz de Fora segue o exemplo de peregrinações nacionais ao Santuário de Nossa Senhora Aparecida, mas também apresenta traços de peregrinações internacionais, como é o caso do Caminho de Santiago de Compostela.

Apesar das peregrinações extrapolarem os limites do contexto local, abrangendo grupos extensos e aglomerados de pessoas, os primeiros estudos antropológicos privilegiaram a coerência local e a integração cultural na compreensão desses eventos, utilizando, para tanto, o mesmo enfoque funcionalista que parecia ser adequado para o estudo das comunidades e sociedades de pequena escala. A perspectiva durkheimiana de um grande festival religioso como unificador do social e regenerador moral se impôs nas ciências sociais como o paradigma de análise do fenômeno das peregrinações. ${ }^{16}$

A peregrinação a Santiago de Compostela é realizada há mais de dez séculos. Tem como ponto de chegada o túmulo do Apóstolo Tiago, na Espanha. São aproximadamente 800 quilômetros trilhados pelos peregrinos a pé ou de bicicleta. ${ }^{17}$

Assim como o modelo de percurso do Caminho de Santiago de Compostela na Espanha, e do Caminho da Fé que liga cidades do interior de Minas Gerais à Aparecida, a Caminhada que sai de Juiz de Fora é resignificada

pelas tradições locais. O propósito dos idealizadores dos caminhos nacionais para peregrinação é possibilitar um lugar para a realização de uma experiência semelhante, no Brasil, àquela vivenciada no caminho

\footnotetext{
${ }^{15}$ MOREIRA, J. C. C., "Caminho da Fé”, p. 51.

${ }^{16}$ CALVELLI, H. G., A "Santiago de Compostela" brasileira, p. 28.

${ }^{17}$ CALVELLI, H. G., A "Santiago de Compostela" brasileira, p. 46.
} 
europeu, bem como a divulgação do turismo, visando ao desenvolvimento econômico das regiões que circundam esses caminhos. ${ }^{18}$

Conta a tradição que quando os apóstolos de Cristo se espalharam pelo mundo, São Tiago passou algum tempo na Galícia, tendo sido preso ao retornar à Palestina. Herodes, rei da Judéia, então ordenou, que se cortasse a cabeça do apóstolo. Seus seguidores conduziram seus restos mortais em um barco, guiado por mãos divinas até a Galícia, onde foram sepultados. No ano de 813, o bispo Teodomiro, da Galícia, encontrou em San Fiz uma tumba de mármore no meio do mato. A tumba foi localizada por um ermitão devido a uma chuva de estrelas sempre no mesmo local. Por isso, o nome Compostela, do latim campus stellae, que significa campo das estrelas. ${ }^{19}$

A Caminhada da Fé de Juiz de Fora segue o exemplo de peregrinações nacionais e internacionais como o Caminho de Santiago de Compostela, na Espanha, que será cursado neste ano por um grupo de peregrinos que percorrem o trecho entre Juiz de Fora e Aparecida.

Conforme os organizadores, a primeira Caminhada a pé que partiu de Juiz de Fora em 2012, contou com a presença de doze homens, que dispunham apenas de barracas, sem outra estrutura. Ao idealizar e planejar o trajeto, Marco Aurélio acreditava que Juiz de Fora sendo uma cidade, majoritariamente católica, ${ }^{20}$ poderia ter um percurso semelhante aos demais com destino à Aparecida: "no primeiro ano, a gente foi no peito e na raça. A gente pegou um carro velho aqui, já conhecia um pouco o trajeto. Foram três em um carro, e fomos marcando: aqui a gente vai dormir. Mas a gente não se organizou muito não. Vamos deixar Deus agir, né?". ${ }^{21}$

Em 2015 as três primeiras mulheres participaram da Caminhada. Em 2018, o arcebispo de Juiz de Fora, Dom Gil Antônio Moreira, celebrou uma Missa às $03 \mathrm{~h}$, antes da saída dos peregrinos, partindo próximo à entrada do Estádio Municipal Radialista Mário Helênio. Cinco participantes tinham mais de 70 anos de idade. Guilherme, era o mais novo com 16 anos e dona Silvia a mais idosa com 75 anos. Em 2019 os peregrinos também saíram do mesmo local após Missa.

\section{A hermenêutica dos testemunhos de uma caminhada da fé}

\footnotetext{
${ }^{18}$ CALVELLI, H. G., A "Santiago de Compostela" brasileira, p. 48.

${ }^{19}$ CALVELLI, H. G., A "Santiago de Compostela" brasileira, p. 46.

${ }^{20}$ CAMPOS, R., Fé na Estrada: "poxa vida, uma cidade igual a nossa. Uma cidade católica, e a gente tem que levar para a nossa cidade".

${ }^{21}$ CAMPOS, R., Fé na Estrada.
} 
A Caminhada da Fé, segundo Brandão, ${ }^{22}$ é promovida sem fins lucrativos. Entretanto cada participante deve contribuir com quatrocentos reais que ajudará nas despesas durante o percurso. Este valor

[...] paga, camisa, boné, a caminhonete, o caminhão, todas as refeições: café da manhã, almoço e jantar. A gente leva um cozinheiro, então são dois motoristas e um cozinheiro que já vai no caminhão e prepara tudo. O cardápio já vai programado daqui [Juiz de Fora]. O valor paga também o ônibus de volta. $\mathrm{O}$ ano passado foram três ônibus especiais. ${ }^{23}$

Durante o ano, realiza-se uma vez ao mês um treino, no tamanho semelhante ao percurso diário do trajeto principal. Um mês antes da Caminhada, cada participante assina uma ficha ciente das condições do propósito. Conforme Brandão, o ano passado, 2018, foi um médico, para caminhar,

só que a gente teve muitos problemas com dois mais idosos. A gente não tem estrutura de médico, nem de nada [...] Inclusive eu tive que passar uma noite, quando a gente estava em São Joaquim. Aí nesse ano a gente teve um cuidado especial e fez uma ficha para quem tem acima de 65 anos, que a família está ciente e que a qualquer hora pode ser chamada. ${ }^{24}$

$\mathrm{Na}$ Caminhada da Fé os peregrinos partem de Juiz de Fora à Aparecida e percorrem cerca de $300 \mathrm{Km}$ pelos seguintes distritos e cidades: Torreões (Juiz de Fora-MG), Santa Bárbara do Monte Verde (MG), São Pedro de Itaguá (MG), Santa Isabel (Valença-RJ), São Joaquim (RJ), Vargem Grande (Resende-RJ), Itatiaia (RJ), Queluz (SP), Cachoeira Paulista (SP) e Aparecida (SP). Segundo Miriam, "tem três dias que se dorme em pousada: perto de Rio Preto, que é um hotel fazenda, em Queluz e Canção Nova". ${ }^{25}$

Em 2016 os caminhantes acordavam às 6h, em alguns lugares paravam, almoçavam e continuavam caminhando. A partir de 2018, mudou-se a logística. Agora, conforme Miriam, os peregrinos se levantam às 03h para tomar o café. Às $04 \mathrm{~h}$, com a meditação do terço, rumam ao percurso pré-determinado, de aproximadamente sete horas diárias. Ao chegar no destino, aguardam até o

\footnotetext{
22 BRANDÃO, M., Fé na Estrada.

${ }^{23}$ BRANDÃO, M., Fé na Estrada.

${ }^{24}$ BRANDÃO, M., Fé na Estrada.

${ }^{25}$ BRANDÃO, M., Fé na Estrada.
} 
último peregrino para que todos possam almoçar juntos: "a tarde e à noite ficam livres para o descanso e para a cura de possíveis machucados". ${ }^{26}$

Uma caminhonete dá o apoio com alimentação de cinco em cinco quilômetros. Nela tem água e frutas. Ela serve, também, para resgatar os caminhantes feridos ou que se sentem mal. Conforme Aurélio: "se alguém machucar, o carro pega e leva a pessoa para onde a gente vai dormir e depois volta de novo para dar apoio ao resto das pessoas que ficaram pra traz". ${ }^{27}$

Além da caminhonete, um caminhão leva toda a bagagem. Resumidamente, Campos explica:

O caminhão que irá transportar todas as bagagens e mantimentos seguirá sempre na frente para que o cozinheiro comece a preparar o almoço. A refeição só será servida quando o último caminhante chegar. Já uma camionete seguirá junto aos romeiros, fazendo paradas a cada $4 \mathrm{~km}$ para fornecer frutas e água. O veículo ainda poderá ser utilizado para quem se machucar ou não estiver se sentindo bem e não puder prosseguir o trajeto a pé. Aliás, o desafio ao próprio limite físico foi um ponto destacado na reunião, cada um de nós deve ter consciência para entender a hora de parar e não comprometer o grupo. ${ }^{28}$

Os peregrinos caminham apenas com uma mochila e água, às vezes até sem a mochila. Notamos que nesse caso "é representado por aquele que faz uso do Caminho em grupos e dispõem de uma infraestrutura ambulante ao longo da rota". ${ }^{29}$ Mirian Brandão reforça em seu discurso que além de condicionamento físico, a fé é a principal motivação para os caminhantes: "é bom se ter um certo condicionamento físico, mas isso não é tudo não".

Em nossa pesquisa, verificamos nos discursos dos romeiros da Caminhada, que a motivação procede da fé que professam em Deus e da devoção à Nossa Senhora Aparecida. Na série "Fé na Estrada", publicada no jornal Tribuna de Minas, a jornalista Regina Campos também aponta tal devoção como norteadora do percurso. Para a repórter kardecista, o objetivo de sua série de reportagens parte de seu interesse em "saber quem são esses devotos e porque eles caminham a pé até o santuário, mostrar a rotina da viagem, as refeições, os alojamentos, os lugares por onde passam os romeiros,

\footnotetext{
${ }^{26}$ BRANDÃO, M., Fé na Estrada.

${ }^{27}$ AURÉLIO, M., Fé na estrada.

${ }^{28}$ CAMPOS, R., Fé na Estrada.

${ }^{29}$ CALVELLI, H. G., A "Santiago de Compostela" brasileira, p. 134.
} 
os voluntários que abrigam e ajudam a alimentar os peregrinos e descobrir a fé que move todas essas pessoas". ${ }^{30}$

Durante a série, observamos nos discursos a composição da rotina diária, que carrega "sacrifícios" que para os caminhantes, não são superiores em relação aos que Jesus Cristo sofreu para a salvação do mundo.

De acordo com Regina Campos, alguns cuidados são realizados todos os dias a fim de que os peregrinos aliviem os percalços de dores e de machucados.

Pomadas e spray analgésicos são espalhados por pernas e costas. Antes de pegar a estrada, pomadas antiassaduras e fitas adesivas dão proteção aos pés. Após a caminhada, água fria da fazenda serviu para aliviar os pés doloridos. Rogo que consigam vencer as dores e o cansaço e cheguem andando ao Santuário de Aparecida. ${ }^{31}$

Tais machucados ameaçam até a chegada ao destino, como percebemos no relato da fisioterapeuta Regina Neves: "hoje eu achei que não fosse conseguir. Apareceram novas bolhas [nos pés], mas com fé a gente vai conseguir chegar". ${ }^{32} \mathrm{Na}$ mesma linha, o relato de Miriam Brandão:

A gente tem algumas artimanhas de peregrinos, como tratar bolhas... Tem todo um processo de furar com uma agulha e deixar uma linha dentro da bolha para drenar. A gente tem os curativos que a gente faz. Lá todo mundo vai aprender a usar absorvente. O absorvente que a gente cola na meia, então ele ameniza o impacto, ele serve de amortecedor para bolha, porque você vai ter que colocar o tênis no dia seguinte. ${ }^{33}$

Tal relato se equipara à observação de Miriam na chegada aos locais de repouso. "Às vezes você chega meio dia, uma hora. Você olha para a cara de todo mundo. Como vão caminhar amanhã?". Todo mundo estourado, passa o resto da tarde curando as bolhas.

Bolhas no pé são comuns. Por isso, a dica é passar pasta de vaselina, calçar duas meias e nunca usar um tênis novo. O calçado para a caminhada deve ser amaciado bem antes da partida. Ainda podem ocorrer

\footnotetext{
${ }^{30}$ CAMPOS, R., Fé na Estrada.

${ }^{31}$ CAMPOS, R., Fé na Estrada.

${ }^{32}$ CAMPOS, R., Fé na Estrada.

${ }^{33}$ BRANDÃO, M., Fé na Estrada.
} 
assaduras na virilha e debaixo dos braços. Também para estes casos, os experientes recomendam o uso de vaselina. ${ }^{34}$

No dia seguinte, conforme Brandão, ${ }^{35}$ "três e meia, quatro horas, tomando o café, tá todo mundo rindo até as orelhas. Parece que curou todo mundo".

Talvez a palavra sofrimento não caiba nesta situação. Acredito que um romeiro com pés cheios de bolhas possa sentir um desconforto, mas não um sofrimento. Mas para entender como isso funciona é preciso estar aqui. É algo que não tem explicação. O corpo dói, mas a alma quer mais, quer ir além, quer se superar. ${ }^{36}$

Além da fé, podemos supor que o entrosamento entre os romeiros reforça a motivação para a Caminhada. No caso de Cléria, observamos na série, o seguinte relato quanto à sandália que apertava o pé e a impossibilitava de caminhar: "“a senhora hoje estava queixando muita dor?', pergunto. 'Sim, mas uma amiga me emprestou a sandália". ${ }^{37}$

Já a professora aposentada Anamaria, recolhe o lixo e limpa os locais onde se hospedam. Na saída para a estrada, puxa o terço e está sempre no pelotão da frente. Gosta de chegar cedo à próxima cidade para deixar tudo pronto para quando todos chegarem. Carrega as malas, arruma os colchonetes para as companheiras que chegam cansadas.

Campos $^{38}$ conta que no meio das dores, o professor de geografia Carlos Ney, nascido em Astolfo Dutra (MG), interage com todos, faz piada e não deixa ninguém desanimar.

Verificamos a partir dos discursos, que a pertença ao grupo e a simples participação na Caminhada, também são estímulos ligados à causa maior de se unir aos demais do grupo no trajeto. Claudio Bonadim, por exemplo, disse que ficou sabendo da Caminhada através de uma reportagem há dois anos. Foi de Brasília para Juiz de Fora, de ônibus (16 horas de viagem). Assim, a peregrinação seria mais do que uma experiência, seria "uma forma de deslocamento espacial, categorias de compreensão, que expressam [...] formas de sociabilidade humana: a peregrinação, remetendo ao modelo de Victor Turner de communitas produtora de um espaço simbólico onde as regras

\footnotetext{
${ }^{34}$ CAMPOS, R., Fé na Estrada.

${ }^{35}$ BRANDÃO, M., Fé na Estrada.

${ }^{36}$ CAMPOS, R., Fé na Estrada.

${ }^{37}$ CAMPOS, R., Fé na Estrada.

${ }^{38}$ CAMPOS, R., Fé na Estrada.
} 
sociais, as hierarquias e os constrangimentos morais são abrogados". ${ }^{39}$

Nos discursos de experiência da fé, apontamos o relato de Miriam Brandão, que em 2016 realizou sua primeira Caminhada. "Eu lembro que eu cheguei lá na primeira reunião, o pessoal me achou assim meio fresca, sabe? Porque eu fui de vestido, de salto. E o povo: quem é essa loira, fresca?". ${ }^{40}$

Para Miriam, sua primeira participação na Caminhada teve um significado especial, pois sua família passava por problemas com um filho, e ela tinha como propósito de "ir não para pagar promessa", mas para se entregar. "Sabe, aquele momento em que eu precisava refletir comigo mesma o meu lado espiritual, alimentar, procurar força para enfrentar problemas. Foi muito marcante!". ${ }^{41}$ O que pode se associar "à experiência de um caminho interior a ser percorrido por cada indivíduo na direção do 'autoconhecimento"”. ${ }^{42}$ Para a jornalista Regina Campos, incluído nessa busca pelo autoconhecimento, o sexto dia de Caminha proporcionou aos peregrinos

sem dúvida, o mais emocionante para todos nós. Pouco após as 4h, no alto de um monte, na saída de São Joaquim (RJ), com os romeiros reunidos, Marco Aurélio Costa, um dos organizadores da jornada, pediu que todos parassem, desligassem suas lanternas, olhassem para o céu e observassem as estrelas e a lua.

$\mathrm{Na}$ escuridão da noite, ele iniciou sua fala louvando a Deus e convidando a todos que refletissem sobre suas vidas. Marco Aurélio mencionou as dores nos pés após seis dias caminhando e afirmou que elas não são maiores que as dores que enfrentamos na vida "lá fora", se referindo aos problemas que todos enfrentamos na luta do dia a dia.

Por várias vezes, em sua fala, se emocionou e levou todos a se emocionarem. Usando palavras de glorificação a Deus, Jesus e Nossa Senhora, Marco Aurélio lembrou o espírito da caminhada, "uma viagem para o interior da alma", reforçando o sentido de transformação por qual todos passam. ${ }^{43}$

Observamos nos depoimentos a experiência com o sagrado no decorrer do percurso, "onde pode-se dizer que a peregrinação marca o tempo e organiza o espaço, deixando para trás o mundo profano e aproximando do sagrado". ${ }^{44}$

\footnotetext{
${ }^{39}$ CALVELLI, H. G., A “Santiago de Compostela” brasileira, p. 31.

${ }^{40}$ BRANDÃO, M., Fé na Estrada.

${ }^{41}$ BRANDÃO, M., Fé na Estrada.

${ }^{42}$ CALVELLI, H. G., A "Santiago de Compostela" brasileira, p. 133.

${ }^{43}$ CAMPOS, R., Fé na Estrada.

${ }^{44}$ CALVELLI, H. G., A "Santiago de Compostela" brasileira, p. 140.
} 
Tem muitos casos, e não são poucos não, de pessoas que caem na exaustão e a gente consegue vencer com o Espírito Santo. É uma coisa abençoada. [...] Então superação, muita devoção, é muita adoração, que a gente entrega tudo à Nossa Senhora e a Deus. O Espírito Santo a gente clama ele direto. Teve pessoas que já travou no meio do caminho, de todo mundo em volta dela, rezando, invocando, aí a pessoa vai. ${ }^{45}$

Para Campos, ${ }^{46}$ a fé demonstrada pelos caminhantes é uma resposta para seu questionamento inicial; uma resposta não dita, e sim vivenciada: "o corpo dói, mas a mente ignora, e as pernas teimam em seguir adiante. O que tenho presenciado nestes dias acompanhando os peregrinos que seguem de Juiz de Fora ao Santuário de Aparecida é algo difícil de ser compreendido por uma pessoa sem fé. A fé vence toda e qualquer dor". ${ }^{47}$

Assim se expressa Brandão: "eu vou te falar uma coisa: essa Caminhada, ela é abençoada. A gente entrega muito prá Deus, né? Então todo mundo vai com esse intuito, é muita superação, é muita fé, é uma coisa muito diferente, então a gente não pensa em coisa ruim". ${ }^{48}$

\section{Conclusão}

Observamos através da série de reportagens "Fé na Estrada", publicada no jornal Tribuna de Minas que a "Caminhada da Fé", assim como outras peregrinações a pé ao Santuário Nacional de Nossa Senhora Aparecida, sugere muito mais que preparo físico, e empenho para a participação dos caminhantes que podem ou não pertencer ao Catolicismo. Haja vista a penetração deste congregado de religiosidade que ultrapassa a pertença religiosa, sendo também uma representação social onde os participantes expressam sua fé e interagem entre si. Conforme os estudos de Calvelli, a ideia central é

de que as peregrinações se apresentam, particularmente nas sociedades modernas e complexas, como arenas onde competem simultaneamente discursos religiosos e seculares, ortodoxias oficiais e interpretações populares de um mesmo código doutrinário, grupos religiosos estabelecidos e seitas proféticas de contestação ao status quo. Assim, toda peregrinação cria e estimula um campo variado de relações

\footnotetext{
${ }^{45}$ BRANDÃO, M., Fé na Estrada.

${ }^{46}$ CAMPOS, R., Fé na Estrada.

${ }^{47}$ CAMPOS, R., Fé na Estrada.

${ }^{48}$ BRANDÃO, M., Fé na Estrada.
} 
religiosas e inter-religiosas, culturais e interculturais, num sistema abrangente de trocas econômicas e políticas. ${ }^{49}$

A Caminhada se transforma para os participantes num ritual de significados e práticas, aliado ao discurso oficial da experiência da fé.

Concluímos, assim como Eade \& Sallnow, acreditando o que "confere à peregrinação um caráter essencialmente universalista, será sua capacidade de absorver e refletir uma multiplicidade de discursos e se capaz de oferecer aos romeiros o que cada um deseja". ${ }^{50}$

\section{Referências bibliográficas}

AURÉLIO, M. Fé na estrada. [jul. 2019]. Entrevistador: Regina Campos. Juiz de Fora: Tribuna de Minas, [2019]. Entrevistas concedidas ao Quadro Fé na Estrada. Disponível em: <http.://tribunademinas.com.br/especiais/fe-naestrada>. Acesso em: 05 ago. 2019.

BRANDÃO, M. Fé na estrada. [jul. 2019]. Entrevistador: Regina Campos. Juiz de Fora: Tribuna de Minas, [2019]. Entrevistas concedidas ao Quadro Fé na Estrada. Disponível em: <http.:/tribunademinas.com.br/especiais/fe-naestrada>. Acesso em: 05 ago. 2019.

CALVELLI, H. G. A "Santiago de Compostela" brasileira: Religião, turismo e consumo na peregrinação pelo Caminho da Fé. Juiz de Fora, 2006. 196 p. Dissertação. Instituto de Ciências Humanas, Universidade Federal de Juiz de Fora. Disponível em: $<$ https://repositorio.ufjf.br/jspui/bitstream/ufff/3262/1/haudreygerminianicalvelli.pdf $>$. Acesso em: 12 Mai. 2019.

CAMPOS, R. Fé na Estrada. Tribuna de Minas, Juiz de Fora, 16 Jun. 2019. Caderno Dois. Disponível em: $<$ http.://tribunademinas.com.br/especiais/fe-naestrada>. Acesso em: 05 Ago. 2019.

EADE, J.; SALLNOW, E. Contesting the Sacred: the Antropology of cristian piligrinage. London and New York: Routledge, 1991.

MENDES, G.; MARCOVICCHIO, M. Nossa Senhora Aparecida. Aparecida Santa Cidade. Roteiro de Dorinho Marques e Dori Neto. Aparecida: Reserva Especial Cinema e Vídeo; Mário Marcovicchio Produções, 1995. 1 videocassete (40 min.), VHS, son., color.

${ }^{49}$ CALVELLI, H. G., A "Santiago de Compostela" brasileira, p. 93.

${ }^{50}$ EADE, J; SALLNOW, E., Contesting the Sacred, p. 15. 
MOREIRA, J. C. C. "Caminho da Fé": pedestrianismo, estados emocionais e reflexões sobre a ambiência. Rio Claro, 2007. 139 p. Dissertação. Instituto de Biociências do Campus de Rio Claro, Universidade Estadual Paulista. Disponível em: $<$ https://repositorio.unesp.br/bitstream/handle/11449/96060/moreira_jcc_me_rcla.pdf ?sequence $=1 \&$ is Allowed $=y>$. Acesso em: 12 Mai. 2019.

SILVEIRA, E. S. Turismo religioso no Brasil: uma perspectiva local e global. Turismo em análise, v.18, n.1, p. 33-51, maio 2007. Disponível em $<$ http://www.revistas.usp.br/rta/article/view/62606/65394. 2007>. Acesso em: 12 Mai. 2019.

\section{Rosiléa Archanjo de Almeida}

Mestranda em Ciência da Religião pela Universidade Federal de Juiz de Fora Juiz de Fora / MG - Brasil E-mail: rosileaarchanjo@yahoo.com.br

Recebido em: 03/09/19

Aprovado em: 20/12/19 